Original Article

\title{
Alcohol use disorders and psychiatric diseases in Colombia
}

\section{Desórdenes y enfermedad psiquiátrica causada por el uso de alcohol en Colombia}

\author{
Hernan G Rincon-Hoyos ${ }^{1,2}$, Alejandro Castillo ${ }^{1,2}$, and Sergio I Prada ${ }^{3}$ \\ ${ }^{1}$ Fundacion Hospital Valle del Lili, Cali, Colombia. \\ ${ }^{2}$ Escuela de Medicina, Universidad ICESI, Cali, Colombia. \\ ${ }^{3}$ Facultad Ciencias Administrativas y Económicas, Departamento de Economía, Universidad ICESI, Cali, Colombia.
}

Rincon-Hoyos HG, Castillo A, Prada SI. Alcohol use disorders and psychiatric diseases in Colombia. Colomb Med (Cali). 2016; 47(1):31-37.

(c) 2016. Universidad del Valle. This is an Open Access article distributed under the terms of the Creative Commons Attribution License, which permits unrestricted use, distribution, and reproduction in any medium, provided the original author and source are credited.

\begin{abstract}
Article history:
Received: 22 June 2015

Revised: 23 December 2015

Accepted: 25 January 2016

\section{Keywords:}

Public health, alcoholism, alcohol abuse, alcoholrelated disorders, epidemiology, mental disorders, mood disorders, Colombia

\section{Palabras clave:}

la salud pública, el alcoholismo, el abuso de alcohol, trastornos relacionados con el alcohol, la epidemiología, trastornos mentales, trastornos del estado de ánimo, Colombia

\section{Abstract Resumen}

Background: An accurate understanding of co-occurrence and Antecedentes: Una comprensión precisa de la co-ocurrencia y la comorbidity of alcohol use disorders (AUD) in Colombia is crucial comorbilidad de los trastornos por consumo de alcohol (AUD) en for public health.

Colombia es crucial para la salud pública.

Objective: A secondary analysis was conducted, using a 2003/2004 Objetivo: Se realizó un análisis secundario, utilizando una base de government's population database to determine the lifetime datos gubernamental de población 2003/2004 para determinar las associations between AUD and other mental and addictive disorders asociaciones de vida entre los trastornos por consumo de alcohol in people of Colombia aged 18-65 years.

$\mathrm{y}$ otros trastornos mentales y adictivos en personas de edades Methods: Several statistical analysis were performed: testing comprendidas entre 18 a 65 años de Colombia.

prevalence difference in mental disorders by whether the individual Métodos: Varios análisis estadísticos se realizaron: pruebas de had an AUD; a stratified analysis by gender and logistic regression diferencia en la prevalencia de los trastornos mentales en función analyses accounting for differences in demographic, socio-economic, de si el individuo tenía un AUD; un análisis estratificado por sexo y behavioral and self-reported health status variables.

análisis de regresión logística teniendo en cuenta las diferencias en Results: People with AUD comprised 9\% of the population, of which las variables del estado de salud, demográficas, socioeconómicas, de $88 \%$ were males and on average 37 years old. They were more likely comportamiento y de auto-reporte.

to be males, be working, and be current smokers; and less likely to be Resultados: las personas con AUD fueron el 9\% de la población, de los at home or retired. The population with AUD had greater chance to cuales $88 \%$ eran varones y en promedio tenían 37 años. Estas personas comply with criteria for all disorders but minor depressive disorder, tenían trabajo y eran fumadores activos; y tenían menos probabilidad post-traumatic stress disorder, nicotine dependence, and oppositional de estar en casa o ser jubilados. La población con AUD tenía mayores defiant disorder.

posibilidades de cumplir con los criterios de todos los trastornos,

Conclusion: This study demonstrates a high prevalence of mental excepto el trastorno depresivo menor, el trastorno de estrés postdisorders in the adult population with AUD in Colombia. The findings traumático, la dependencia a la nicotina, y el trastorno oposicional highlight the importance of comorbidity as a sign of disease severity desafiante.

and impact on public health and supports the need for training of Conclusión: Este estudio demuestra una alta prevalencia de trastornos more professionals and developing appropriate interventions and mentales en la población adulta con trastornos por consumo de services.

alcohol en Colombia. Los resultados destacan la importancia de la comorbilidad como un signo de gravedad de la enfermedad e impacto en la salud pública y apoyan la necesidad de formación de más profesionales y el desarrollo de intervenciones y servicios apropiados.
\end{abstract}

Corresponding author:

Hernan G. Rincon Hoyos. Fundación Valle del Lilí. Cra. 98 \# 18-49, Oficina Torre 1 (207). Cali, Colombia. Phone: +57 (2) 3319090, extensión

243. Email: hernangrincon@gmail.com. 


\section{Introduction}

Mental and Substance Abuse Disorders have been described worldwide as leading causes in years of life lost to premature mortality (YLLs), to the point that perhaps only through making their prevention and treatment a health priority is possible in a country like Colombia to improve the health of the population ${ }^{1}$.

The World Health Organization (WHO) indicates that approximately $48 \%$ of the world population aged 15 years or older consume alcoholic beverages and $16 \%$ of drinkers engage in heavy episodic drinking ${ }^{2}$. The global burden of harm attributable to alcohol use for different developing world regions is highest for Latin America and the Caribbean, where 9.7\% of the Disability Adjusted Life Years (DALYs) and $4.5 \%$ of all deaths are attributed to alcohol-related problems ${ }^{3}$; while worldwide in 2012 alcohol consumption were estimated to cause 3.3 million deaths (5.9\% of all global deaths) and 139 million DALYs ${ }^{2}$.

In both developing and developed countries, alcohol use has been shown to cause significant harm to the physical, psychological, and social health of individuals, families, and communities ${ }^{4,5}$; and it has also been linked to negative effects on the criminal justice system, employment sector, and economic and social development ${ }^{6}$.

High-income countries have the highest alcohol per capita consumption and the highest prevalence of heavy episodic drinking among drinkers. But, alcohol is used by people of all ages and socioeconomic groups, and drinking starts usually early during adolescence ${ }^{7,8}$. People with lower socioeconomic status appear to be more vulnerable to tangible problems and consequences of alcohol consumption ${ }^{9}$.

There is substantial evidence to state that excessive alcohol is causally related to risky behaviors and co-morbidly related to the several mental diseases that may differ by gender ${ }^{10,11}$, including common violence ${ }^{12}$; family violence; traffic accidents; intentional and non-intentional trauma; and sexually-HIV risky behavior; all of them are important public health problems related to alcohol heavy use $\mathrm{e}^{13,14}$. The use of psychoactive substances can occur frequently in conjunction with alcohol, further increasing high-risk behaviors ${ }^{15}$. In addition, behavioral disorders, anxiety, depression, mania and other psychiatric disorders are frequently associated to alcohol heavy use ${ }^{10,16}$.

The National Epidemiologic Survey on Alcohol and Related Conditions (NESARC) has provided detailed data on comorbidity of Alcohol Use disorders (AUD) with drug use disorders, confirming the high levels of association described in previous studies ${ }^{17,18}$. In these studies drug use disorders and comorbidity were more likely to be observed among youth, men, non-married and those of lower socioeconomic status than the AUD-only group. Clinical complexity, costs and disabilities associated with alcohol use disorders, are enhanced by the comorbidity and co-occurrence of other psychiatric disorders, which have been reported in numerous clinical studies ${ }^{17}$.

Information about the co-occurrence and comorbidity of alcohol disorders in Colombia is limited to few reports showing high prevalence $^{19,20}$. The Colombian Government decree 3039 of 2007, adopted the National Public Health Plan, stating mental health as one of the priorities and alcohol and substance use control as one of the goals to achieve ${ }^{8}$. The Colombian Mental Health Survey (CMHS), conducted in 2003-4, revealed a high lifetime prevalence of anxiety disorders (19.3\%), mood disorders (15.0\%) and substance disorders (10.6\%). Of particular concern, $94.7 \%$ of those who had a substance disorder did not use health services ${ }^{21,22}$. The last substance use survey done in Colombia in 2013 concluded there is an increase of substance use with regard to previous studies ${ }^{23}$, therefore suggesting the need to understand comorbidity. The Colombian Mental Health Survey of 2015 used different approach than in 2003, excluding the determination of frequency of some disorders like Schizophrenia, PTSD and Alcohol and Substance Disorders ${ }^{24}$, hence not allowing the possibility to further investigate comorbidity of AUD with all mental disorders. Base on the stated, it could be argue than an accurate understanding of this observable fact is crucial to prevention and development of improved treatment for people who meet criteria for two or more disorders in different clinical settings of developed and developing countries $^{25}$.

This population based study was conducted to determine the lifetime associations between AUD and other mental and addictive disorders in men and women of Colombia aged 18-65 years, through a secondary analysis of the CMHS of 2003/2004.

\section{Materials and Methods}

This secondary analysis used the CMHS database 2003-2004 (Colombian Ministry of Health and Social Protection) to obtain information regarding the co-occurrence of mental disorders and AUD. The data was recently released as public use files ${ }^{26}$. The survey was conducted in an urban population of 5,526 homes; 4,544 one-on-one interviews with adults were completed with an $87 \%$ response rate based on a national level probabilistic, multistage, and stratified sample. Survey participants comprised a noninstitutionalized population between the ages of 18-65 years with established residency in five Colombian regions.

The sample released to the public has 4,426 individuals. A full description of sampling procedures and other methodological details on the survey is described elsewhere ${ }^{21}$. The survey used internal subsampling to reduce respondent burden by dividing the interview in two parts. Part 1 included core diagnostic assessment $(\mathrm{N}=4,426)$. Part 2 included information about correlates and disorders of secondary interest. All respondents completed part 1. All part-1 respondents who met criteria for any disorder and a subsample of approximately $25 \%$ of others were administered part $2(\mathrm{~N}=2,442)$.

The survey used a computerized version of the Composite International Diagnostic Interview (CIDI; $15^{\text {th }}$ registered version) that provides diagnoses in agreement with the DSM-IV and ICD10. Disorder indicators were not released with public use files. To identify those with lifetime prevalence, the authors followed definitions and criteria of the Diagnostic and Statistical Manual of Mental Disorders, Fourth Edition (DSM-IV). 
To test lifetime prevalence difference in mental disorders by whether the individual was alcohol user o not a Fischer's exact test was conducted. AUD was defined for those with alcohol abuse or dependence according to the original study following international literature. In addition, a stratified analysis by gender was also performed. Lastly, to test whether differences observed in prevalence estimates held after accounting for differences in demographic, socio-economic, behavioral and selfreported health status variables, logistic regression analyses were performed. All analyses were conducted in Stata ${ }^{\circledR} 13$ using survey data commands. Survey design variables such as primary sample units (PSU) and survey weights were used in all estimations.

Demographic variables included in logistic regressions were age, sex and marital status. The latter was coded as four independent binary variables: married, separated/divorced, widowed and never married. Never married was the reference category. To account for non-linear effects due to age, age is included in levels and to the square.

Socioeconomic variables included in logistic regressions were education and occupation. Education status was coded as elementary, high school dropout, high school, and undergraduate studies (includes both those that finished and those that did not); elementary dropout (including those that never attended) was the reference category. Occupation status was coded as four independent binary variables: working, studying, housewife or retired, and other. Other was the reference category.

Behavioral variables included in regression analyses were obesity and smoking. Obesity/overweight was coded as a dichotomous variable that took the value of 1 for individuals with a BMI (Body Mass Index) greater than 25. Smoking was coded as a dichotomous variable. Self-reported health status variables were "Excellent/ Very-Good", "Good" and "Fair or Bad". "Excellent/Very-Good" was the reference category.

\section{Results}

Table 1 shows socio-demographic and behavioral characteristics on both populations of interest. In particular, people with AUD comprised $9 \%$ of the population, of which $88 \%$ were males and on the average 37 years old. The predominant marital status was never married (56\%) followed by married (31\%). Over 30\% of these had high levels of education (undergraduate), and $74 \%$ reported their occupational status as working. Obesity was a characteristic for almost $8 \%$ of this population, and $28 \%$ were smokers at the time of interview. Lastly, $41 \%$ of people with AUD self-reported their health status as good.

When compared to the population of alcohol non users, people with AUD were more likely to be males, be working, and be current smokers; and less likely to be at home or retired using a 5\% significance level. At a $10 \%$ significance level, they also seemed to be less likely to be high school graduates, to be in excellent/good health and more likely to be in fair/bad health.

Table 2 shows prevalence estimates of mental disorders for the total population; Table 3 for males and females, and present statistical tests on differences in prevalence by whether individuals have
Table 1. Characteristics of survey participants by alcohol use disorders status.

\begin{tabular}{|c|c|c|c|}
\hline & AUD $\ddagger$ & No AUD $\ddagger$ & $p$-value \\
\hline \multicolumn{4}{|l|}{ Demographic characteristics } \\
\hline Age (Years) & $37.0(1.062)$ & $36.7(0.299)$ & 0.774 \\
\hline Male $(\%)$ & $88.2(0.019)$ & $41.3(0.012)$ & $<0.001^{*}$ \\
\hline \multicolumn{4}{|l|}{ Marital status } \\
\hline Married & $30.7(0.039)$ & $33.5(0.010)$ & 0.484 \\
\hline Separated/divorced & $11.1(0.023)$ & $9.3(0.005)$ & 0.389 \\
\hline Widowed & $1.9(0.009)$ & $3.6(0.004)$ & 0.192 \\
\hline Never married (Reference) & $56.3(0.040)$ & $53.6(0.011)$ & 0.514 \\
\hline \multicolumn{4}{|l|}{ Socioeconomic characteristics } \\
\hline \multicolumn{4}{|l|}{ Education } \\
\hline Elementary & $11.6(0.021)$ & $13.4(0.007)$ & 0.446 \\
\hline High School Dropout & $24.2(0.030)$ & $24.1(0.010)$ & 0.980 \\
\hline High School & $16.4(0.025)$ & $21.7(0.010)$ & 0.070 \\
\hline Undergraduate & $30.6(0.043)$ & $24.9(0.012)$ & 0.183 \\
\hline Elementary Dropout (Reference) & $17.1(0.027)$ & $15.8(0.007)$ & 0.637 \\
\hline \multicolumn{4}{|l|}{ Occupation Status } \\
\hline Working & $74.0(0.038)$ & $54.9(0.012)$ & $<0.001^{*}$ \\
\hline Studying & $4.8(0.030)$ & $7.4(0.010)$ & 0.497 \\
\hline Home or Retired & $9.9(0.024)$ & $26.9(0.009)$ & $<0.001 *$ \\
\hline Unemployed (Reference) & $11.3(0.021)$ & $10.8(0.008)$ & 0.798 \\
\hline \multicolumn{4}{|l|}{ Behavioral characteristics } \\
\hline Obese & $7.7(0.017)$ & $6.6(0.005)$ & 0.507 \\
\hline Current Smoker & $28.4(0.040)$ & $13.1(0.006)$ & $<0.001 *$ \\
\hline \multicolumn{4}{|l|}{ Self-Reported Health } \\
\hline Excellent/Very Good (Reference) & $28.0(0.033)$ & $34.8(0.012)$ & 0.065 \\
\hline Good & $41.3(0.039)$ & $41.1(0.011)$ & 0.960 \\
\hline Fair/Bad & $30.7(0.039)$ & $24.1(0.010)$ & 0.076 \\
\hline $\mathrm{N}$ & 325 & 4,101 & \\
\hline
\end{tabular}

alcohol abuse/dependency problems. For all individuals and for males, all mental disorders studied were more prevalent for people with AUD with the exception of minor depressive disorders, PTSD, nicotine dependency, and oppositional defiant disorder. For females, five mental disorders were more prevalent among persons with AUD: major depressive disorder, drug abuse, separation anxiety, oppositional defiant disorder, and conduct disorder.

Regression analyses are reported in Table 4 . The table only reports the OR for the AUD population; nonetheless the regression analyses included all variables described in Table 1 as regressors. In that sense the results reported are ORs after accounting for

Table 2. Lifetime prevalence of mental disorders by alcohol use disorder status.

\begin{tabular}{|c|c|c|c|}
\hline & AUD $\ddagger$ & No AUD $\ddagger$ & $p$-value \\
\hline Number of interviewees & 325 & 4,101 & \\
\hline \multicolumn{4}{|l|}{ Mood Disorders } \\
\hline Major Depressive Disorder & $17.0(0.025)$ & $10.2(0.010)$ & $0.004^{*}$ \\
\hline Minor Depressive Disorder & $1.7(0.008)$ & $2.1(0.003)$ & $0.716^{*}$ \\
\hline Bipolar I & $7.3(0.031)$ & $1.5(0.003)$ & $<0.001^{*}$ \\
\hline \multicolumn{4}{|l|}{ Anxiety Related Disorders } \\
\hline Agoraphobia & $5.2(0.017)$ & $2.2(0.003)$ & $0.016^{*}$ \\
\hline Post-Traumatic Stress Disorder & $2.0(0.008)$ & $1.3(0.002)$ & $0.346^{*}$ \\
\hline \multicolumn{4}{|l|}{ Substance Use Related Disorders } \\
\hline Drug Abuse & $7.0(0.016)$ & $0.3(<0.001)$ & $<0.001^{*}$ \\
\hline Drug Dependency & $5.2(0.013)$ & $0.2(<0.001)$ & $<0.001 *$ \\
\hline Nicotine Dependency & $3.2(0.014)$ & $1.3(0.002)$ & $0.053^{*}$ \\
\hline \multicolumn{4}{|l|}{ Other Disorders } \\
\hline Separation Anxiety & $13.6(0.033)$ & $5.6(0.004)$ & $<0.001^{*}$ \\
\hline Oppositional Defiant Disorder & $3.1(0.014)$ & $1.6(0.003)$ & $0.137^{*}$ \\
\hline Conduct Disorder & $5.4(0.013)$ & $1.0(0.002)$ & $<0.001 *$ \\
\hline
\end{tabular}


Table 3. Lifetime prevalence of mental disorders for males by alcohol use disorder status.

\begin{tabular}{|c|c|c|c|c|c|c|}
\hline & \multicolumn{3}{|c|}{ Males } & \multicolumn{3}{|c|}{ Females } \\
\hline & AUD $\ddagger$ & No AUD $\ddagger$ & $p$-value & AUD & No AUD & $p$-value \\
\hline Number of interviewees & 265 & 1,435 & & 60 & 2,666 & \\
\hline \multicolumn{7}{|l|}{ Mood Disorders } \\
\hline Major Depressive Disorder & $14.4(0.025)$ & $5.7(0.008)$ & $<0.001^{*}$ & $37.10(0.076)$ & $13.40(0.014)$ & $<0.001^{*}$ \\
\hline Minor Depressive Disorder & $1.9(0.009)$ & $1.6(0.003)$ & 0.710 & & & \\
\hline Bipolar I & $7.7(0.035)$ & $1.2(0.003)$ & $<0.001^{*}$ & $4.12(0.023)$ & $1.69(0.004)$ & 0.143 \\
\hline \multicolumn{7}{|l|}{ Anxiety Related Disorders } \\
\hline Agoraphobia & $5.2(0.019)$ & $0.9(0.002)$ & $<0.001^{*}$ & $4.73(0.028)$ & $3.11(0.004)$ & 0.500 \\
\hline Post-Traumatic Stress Disorder & $1.8(0.008)$ & $0.6(0.002)$ & 0.074 & $3.52(0.028)$ & $1.76(0.003)$ & 0.402 \\
\hline \multicolumn{7}{|l|}{ Substance Use Related Disorders } \\
\hline Drug Abuse & $7.5(0.177)$ & $0.6(0.002)$ & $<0.001^{*}$ & $2.82(0.020)$ & $0.04(<0.001)$ & $<0.001^{*}$ \\
\hline Drug Dependency & $5.9(0.149)$ & $0.2(0.001)$ & $<0.001^{*}$ & $0.27(0.002)$ & $0.17(0.003)$ & 0.689 \\
\hline Nicotine Dependency & $3.4(0.016)$ & $1.6(0.003)$ & 0.147 & $2.06(0.150)$ & $1.13(0.002)$ & 0.422 \\
\hline \multicolumn{7}{|l|}{ Other Disorders } \\
\hline Separation Anxiety & $13.1(0.037)$ & $3.8(0.006)$ & $<0.001^{*}$ & $17.53(0.051)$ & $6.76(0.005)$ & $0.002 *$ \\
\hline Oppositional Defiant Disorder & $2.8(0.014)$ & $2.2(0.005)$ & 0.696 & $5.86(0.033)$ & $1.16(0.002)$ & $0.003^{*}$ \\
\hline Conduct Disorder & $5.4(0.013)$ & $1.3(0.003)$ & $<0.001^{*}$ & $5.75(0.027)$ & $0.69(0.001)$ & $<0.001^{*}$ \\
\hline
\end{tabular}

$\mp$ Percentage (Standard error)

*Statistically significant $(p<0.05)$. For $(\%)$ variables Fischer's exact test is reported

Minor Depressive disorder not included because there were no observations for females that have alcohol abuse/dependency problems.

differences in demographic, socio-economic, behavioral and self-reported health status variables. As shown in Table 4 the population with alcohol AUD were more likely to be diagnosed with all disorders but minor depressive disorder, PTSD, nicotine dependence, and ODD.

\section{Discussion}

This study, to our knowledge, represents the first analysis of AUD comorbidity with other mental disorders in Colombia. Our results demonstrate a high prevalence of Major Depression, Bipolar I Disorder, Agoraphobia, Drug Abuse, Drug Dependence, Separation Anxiety and Conduct Disorder in the adult population of Colombia with Alcohol Use Disorders, confirming what has been shown elsewhere ${ }^{27,28}$. To highlight the importance of these results for Colombia, a recent international report suggested that the "burden of disease attributable to the use of legal substances clearly outweighs the use of illegal drugs and a large part of the substance-attributable burden would be avoidable if known effective interventions were implemented"29. Furthermore, the problematic use of alcohol is frequently underdiagnosed and undertreated; as a matter of fact, in

Table 4. Adjusted Lifetime Odd Ratios of Mental Disorders for Alcohol Use Disorder subjects.

\begin{tabular}{|c|c|c|c|c|}
\hline \multirow{2}{*}{ Mood Disorders } & \multicolumn{2}{|c|}{ OR $p$-value* } & \multicolumn{2}{|c|}{$95 \% \mathrm{CI}$} \\
\hline & & & & \\
\hline Major Depressive Disorder & 2.73 & $<0.001$ & 1.74 & 4.29 \\
\hline Minor Depressive Disorder & 0.89 & 0.835 & 0.31 & 2.55 \\
\hline Bipolar I & 5.14 & $<0.001$ & 2.33 & 11.36 \\
\hline \multicolumn{5}{|l|}{ Anxiety Related Disorders } \\
\hline Agoraphobia & 3.95 & $<0.001$ & 1.97 & 7.91 \\
\hline Post-Traumatic Stress Disorder & 2.02 & 0.153 & 0.77 & 5.27 \\
\hline \multicolumn{5}{|l|}{ Substance Use Related Disorders } \\
\hline Drug Abuse & 12.74 & $<0.001$ & 5.22 & 31.08 \\
\hline Drug Dependence & 20.72 & $<0.001$ & 9.60 & 44.75 \\
\hline Nicotine Dependence & 1.92 & 0.310 & 0.70 & 5.27 \\
\hline \multicolumn{5}{|l|}{ Other disorders } \\
\hline Separation Anxiety & 3.33 & $<0.001$ & 1.87 & 5.90 \\
\hline Oppositional Defiant Disorder & 1.48 & 0.443 & 0.54 & 4.01 \\
\hline Conduct Disorder & 3.56 & $<0.001$ & 1.76 & 7.21 \\
\hline
\end{tabular}

Latin America, alcohol consumption is $50 \%$ greater than the world's mean and almost three-fourths of people who abuse or depend on alcohol have never received any psychiatric treatment ${ }^{30,31}$. At this respect, the access to services for mental health disorders in Colombia is low (40\%) suggesting a great need of psychiatric care for the severely ill population reported ${ }^{22,24}$.

The strong relationship found between bipolar 1 disorder and AUD, has been reported elsewhere to be associated with medication non-compliance, more mixed or dysphoric episodes, and more hospital admissions ${ }^{32}$ with great impact to health care cost ${ }^{17}$, which further emphasize the necessity for early identification and care in Colombia. As a possible explanation for this relationship, some researchers have hypothesized that alcohol consumption is a form of self-medication ${ }^{33}$. The comorbidity found was greater in men than women, but when compared with healthy women, the comorbidity in women was greater than in men $^{7}$.

With further analysis by gender, we were able to find a correlation between AUD and major depression in Colombian men and women; and between anxiety disorders and alcohol abuse in men, particularly in those with agoraphobia and social anxiety perhaps reinforcing each other as have been suggested ${ }^{34,35}$. At this respect, comorbidity with major mood and anxiety disorders that develop independently of acute intoxication and withdrawal are among the most prevalent psychiatric disorders around the world and have been reported consistently associations between alcohol use disorders and mood and anxiety disorders ${ }^{3,7,36}$.

In the Colombian population, heterotypic comorbidity was found, as well as homotypic comorbidity with other substance dependence disorders, including nicotine dependence ${ }^{37}$. Current analyses revealed that homotypic and heterotypic comorbidity were different in men than women, similar to previous reports showing that women drink less alcohol and have fewer problems related to alcohol consumption and $\mathrm{AUD}^{20}$.

In a cluster analysis of the US National ComorbiditySurvey it was described that three highly co-morbid classes represented $7 \%$ of the population and $43.6 \%$ of the serious cases were represented by alcohol use disorder co-morbidities ${ }^{27}$. Other studies have indicated 
that alcohol disorder comorbidity with substance disorders with externalizing disorders, could have an underlying etiology contrasting with comorbidity with internalizing disorders like depressive or anxiety disorders that seem to be related to shared etiology factors between the comorbid disorders ${ }^{38}$. Disruptive behavior disorders, like conduct disorder or oppositional defiant disorder, have been reported to be the most common co-morbid condition in adolescents with alcohol disorders. Moreover, prospective studies indicate that conduct disorders are the most predictive of subsequent substance use disorder ${ }^{39}$.

As an important contribution to understanding and validating the impact of mental disorders comorbidity on physical health in Colombia, in our study the perception of health in the AUD population was found to be lower suggesting greater risk for adverse general health outcomes ${ }^{40}$. Comorbidity and cooccurrence of mental disorders and AUD have been associated with greater symptom severity, disability, unrelenting disease course and lower treatment outcome $e^{17,38,41}$. It should also be noted that this population has been reported to use health services more frequently than the general population ${ }^{17,38}$. In addition, comorbidity is frequently found a risk factor for health \& HIV risk behaviors $^{42,43}$.

The positive health consequences of delaying or moderating the consumption of alcohol use cannot be overstated. It would decrease the incidence of developmental and neurological deficits, traffic accidents, delinquency, psychiatric disorders, high blood pressure, HIV and HIV sex-risk behaviors ${ }^{44-46}$.

Furthermore, lessening alcohol consumption could also improve the likelihood of better physical, emotional development through less interference with how people approach and experience interactions; and also perhaps decrease the incidence of psychiatric and substance abuse disorders, helping to close the reinforcing cycle $\mathrm{e}^{47}$. Appropriately handling of the problem of early drinking should improve the normal delay expected in cognitive and social-emotional development associated with substance use during adolescence resulting in better academic performance, self-esteem, and family and social interactions ${ }^{48,49}$.

Consistent with other studies of AUD and other mental disorders ${ }^{22,34}$, the findings suggest that substance disorders are correlated with AUD in Colombians and more prevalent than in the general population. To further investigate is why there were not found associations with posttraumatic stress disorder as previously reported in the literature ${ }^{48}$. The findings strongly highlight the importance of comorbidity as a sign of disease severity and supports the need for training of more professionals and developing appropriate interventions and services ${ }^{50,51}$.

\section{Limitations}

The National Survey method used in this study provided quality data in order to run this secondary analysis with the advantage of enabling co-morbidities to be evaluated in a time-efficient manner and without duplication of efforts and at a lower research cost. Nonetheless, it is necessary to mention that this secondary analysis was not an objective of the original survey; therefore, some type of bias can be expected ${ }^{4}$. Additionally, the present cross-sectional study design does not allow inferring causality relationships between AUD and other mental disorders. Although the original data is from 2003, the authors do not have a reason to believe that the prevalence of disorders studied could have decreased during these years, since no interventions have been reported, on the contrary according to the substance abuse survey the prevalence of AUD seems to be increasing ${ }^{23}$.

\section{Conclusion}

The findings of this study clearly suggest that the co-occurrence of AUD and other mental disorders is prevalent among Colombian men and women, raising concern, and underscoring the importance of providing health services and developing community interventions to confront this public health issue.

Acknowledgements:

Johnny Campiño provided excellent research assistance. Preliminary analyses done before 2010, which did not conduct to a publication, were presented at two academic meetings and were partially supported by the Corporación de Lucha Contra el Sida de Cali, Colombia; and the Fogarty International Research Training Center at University of Miami under the mentorship of Gail ShorPosner and John Lewis (NIH/Fogarty 043 TW00017).

Conflict of Interest:

All authors do not have any possible conflicts of interest

\section{References}

1. Whiteford HA, Degenhardt L, Rehm J, Baxter AJ, Ferrari AJ, Erskine HE, et al . Global burden of disease attributable to mental and substance use disorders: findings from the Global Burden of Disease Study 2010. Lancet. 2013; 382(9904): 1575-86.

2. World Health Organization. Global status report on alcohol and health 2014. Geneva: World Health Organization; 2014.

3. Cranford JA, Nolen-Hoeksema S, Zucker RA. Alcohol involvement as a function of co-occurring alcohol use disorders and major depressive episode: evidence from the National Epidemiologic Survey on Alcohol and Related Conditions. Drug Alcohol Depend. 2011; 117(2-3): 145-51.

4. Edwards G. Alcohol policy and the public good. Addiction. 1997; 92(1): S73-9.

5. Room RC-CB, Gureje O, Jernigan D, Maskela K, Marshall $\mathrm{M}$, et al . Alcohol in a changing world.Cambridge: Cambridge University Press; 2003.

6. Parry $\mathrm{CDH}$. Alcohol problems in developing countries: challenges for the new millennium. Suchtmed. 2000; 2(4): 216-20.

7. Di Florio A, Craddock N, van den Bree M Alcohol misuse in bipolar disorder. A systematic review and meta-analysis of comorbidity rates. Eur Psychiatry. 2014; 29(3): 117-24.

8. Ministerio de la Protección Social . Estudio Nacional de Consumo de Drogas en Colombia (Resumen Ejecutivo) Bogotá: Dirección Nacional de Estupefacientes, editor; 2009. 
9. Grittner U, Kuntsche S, Graham K, Bloomfield K. Social inequalities and gender differences in the experience of alcoholrelated problems. Alcohol and alcoholism. 2012; 47(5): 597-605.

10. Ilomäki R, Södervall J, Ilomäki E, Hakko H, Räsänen P, STUDY-70 Workgroup. Drug-dependent boys are more depressed compared to girls: a comorbidity study of substance dependence and mental disorders.European Addiction Research. 2008; 14(3): 161-8.

11. Dyster-Aas J, Willebrand M, Wikehult B, Gerdin B, Ekselius L. Major depression and posttraumatic stress disorder symptoms following severe burn injury in relation to lifetime psychiatric morbidityJ. Trauma.2008; 64(5): 1349-56.

12. Pulay AJ, Dawson DA, Hasin DS, Goldstein RB, Ruan WJ, Pickering RP, et al . Violent behavior and DSM-IV psychiatric disorders: results from the national epidemiologic survey on alcohol and related conditions. J Clin Psychiatry. 2008; 69(1): 12-22.

13. National Institute on Alcohol Abuse and Alcoholism. Alcohol and AIDS.A guide to research issues and opportunities. Bethesda: NIAAA; 2001.

14. Rehm J, Monteiro M. Alcohol consumption and burden of disease in the Americas: implications for alcohol policy. Revista Panamericana de Salud Pública $=$ Pan American Journal of Public Health.2005; 18(4-5): 241-8.

15. D'Onofrio G, Becker B, Woolard RH. The impact of alcohol, tobacco, and other drug use and abuse in the emergency department. Emerg Med Clin North Am. 2006; 24(4): 925-67.

16. Gilder DA, Lau P, Gross A, Ehlers CL. A comorbidityof alcohol dependence with other psychiatric disorders in young adult Mexican Americans. J Addict Dis. 2007; 26(4): 31-40.

17. Schuckit MA. Comorbidity between substance use disorders and psychiatric conditions. Addiction. 2006; 101(1): 76-88.

18. Falk D, Yi HY, Hiller-Sturmhofel S. An epidemiologic analysis of co-occurring alcohol and drug use and disorders: findings from the National Epidemiologic Survey of Alcohol and Related Conditions (NESARC) Alcohol research \&amp; health : the journal of the National Institute on Alcohol Abuse and Alcoholism. 2008; 31(2): 100-10.

19. Rincon HG, Granados M, Unutzer J, Gomez M, Duran R, Badiel $\mathrm{M}$, et al. Prevalence, detection and treatment of anxiety, depression, and delirium in the adult critical care unit. Psychosomatics. 2001; 42(5): 391-6.

20. Castillo A, Rincon-Hoyos HG, Lewis JE, Velez JD, Bersh S, Penedo F, et al. Psychosocial and clinical characteristics and psychiatric comorbidityamong men and women with HIV/AIDS under medical treatment at a tertiary health care center in Cali, Colombia. Rev Colomb Psiquiatr. 2008; 37(1): 29-39.

21. Gobierno de la Republica de Colombia.Estudio Nacional de Salud Mental - Colombia 2003. Cali: Minprotección - Fundacion FES Social; 2005.
22. Posada-Villa JA, Aguilar-Gaxiola SA, Magaña CG, Gómez LC. Prevalencia de trastornos mentales y uso de serviciosresultados preliminares del Estudio Nacional de Salud Mental, Colombia, 2003. Rev Colomb Psiquiatr. 2004; 33(3): 41-62.

23. Minjusticia-Minsalud-UNODC-CICAD-OEA-INL, editor. Bogotá: Observatorio de Drogas de Colombia; 2013. Gobierno de la Republica de Colombia. Estudio nacional de consumo de sustancias psicoactivas en Colombia.

24. Minsalud-Colciencias. Encuesta Nacional de Salud Mental 2015 Tomo 1. Bogota: Javergraf; 2015.

25. Clark BJ, Moss M. Secondary prevention in the intensive care unit: does intensive care unit admission represent a "teachable moment?". Crit Care Med. 2011; 39(6): 1500-6.

26. Gobierno Nacional de la República de Colombia. Temática Salud, Estudios e Investigaciones. Bogota: Minsalud; [2016 January 21 ]. Available from: http://www.minsalud.gov.co/ Paginas/Documentos.aspx.

27. Kessler RC, Chiu WT, Demler O, Merikangas KR, Walters EE. Prevalence, severity, and comorbidity of 12-month DSM-IV disorders in the National Comorbidity Survey Replication. Arch Gen Psychiatry. 2005; 62(6): 617-27.

28. Degenhardt L, Chiu WT, Sampson N, Kessler RC, Anthony JC, Angermeyer $\mathrm{M}$, et al . Toward a global view of alcohol, tobacco, cannabis, and cocaine use: findings from the WHO World Mental Health Surveys. PLoS Med. 2008; 5(7): e141.

29. Rehm J, Taylor B, Room R. Global burden of disease from alcohol, illicit drugs and tobacco. Drug Alcohol Rev. 2006; 25(6): 503-13.

30. Kohn R, Levav I, de Almeida JM, Vicente B, Andrade L, Caraveo-Anduaga JJ, et al. Mental disorders in Latin America and the Caribbean: a public health priority. Rev Panam Salud Publica.2005; 18(4-5): 229-40.

31. Babor TF, Higgins-Biddle JC, Saunders JB, Monteiro MG. AUDIT. 2. Geneva: World Health Organization; 2001.

32. Merikangas KR, Akiskal HS, Angst J, Greenberg PE, Hirschfeld RM, Petukhova M, et al . Lifetime and 12-month prevalence of bipolar spectrum disorder in the National Comorbidity Survey replication.Arch Gen Psychiatry. 2007; 64(5): 543-52.

33. Le Strat Y, Gorwood P. Does lower response to alcohol explain the high comorbidity between bipolar disorder and alcohol dependence. Med Hypotheses. 2008; 71(1): 81-4.

34. Grant BF, Stinson FS, Dawson DA, Chou SP, Dufour MC, Compton W, et al . Prevalence and co-occurrence of substance use disorders and independent mood and anxiety disorders: results from the National Epidemiologic Survey on Alcohol and Related Conditions. Arch Gen Psychiatry. 2004; 61(8): 807-16. 
35. Fergusson DM, Boden JM, Horwood LJ. Structural models of the comorbidity of internalizing disorders and substance use disorders in a longitudinal birth cohort. Soc Psychiatry Psychiatr Epidemiol. 2011; 46(10): 933-42.

36. Schneier FR, Foose TE, Hasin DS, Heimberg RG, Liu SM, Grant BF, et al. Social anxiety disorder and alcohol use disorder comorbidityin the National Epidemiologic Survey on Alcohol and Related Conditions. Psychol Med. 2010; 40(6): 977-88.

37. Falk DE, Yi HY, Hiller-Sturmhöfel S. An epidemiologic analysis of co-occurring alcohol and tobacco use and disorders: findings from the National Epidemiologic Survey on Alcohol and Related Conditions. Alcohol Res Health. 2006; 29(3): 162-71.

38. Hasin DS, Stinson FS, Ogburn E, Grant BF. Prevalence, correlates, disability, and comorbidity of DSM-IV alcohol abuse and dependence in the United States: results from the National Epidemiologic Survey on Alcohol and Related Conditions. Arch Gen Psychiatry. 2007; 64(7): 830-42.

39. Moss HB, Lynch KG. Comorbid disruptive behavior disorder symptoms and their relationship to adolescent alcohol use disorders. Drug Alcohol Depend. 2001; 64(1): 75-83.

40. Ul-Haq Z, Mackay DF, Pell JP. Association between SelfReported General and Mental Health and Adverse Outcomes: A Retrospective Cohort Study of 19625 Scottish Adults. PloS One. 2014; 9(4): e93857.

41. Compton III WM, Cottler LB, Jacobs JL, Ben-Abdallah A, Spitznagel EL. The Role of Psychiatric Disorders in Predicting Drug Dependence Treatment Outcomes. Am J Psychiatry. 2003; 160(5): 890-5.

42. Knox T, Jerger L, Tang A. Alcohol, HIV/AIDS, and Liver Disease. In: Watson RR, Preedy VR, Zibadi S, editors. Alcohol, Nutrition, and Health Consequences. Nutrition and Health: Humana Press; 2013. pp. 287-303.
43. Hensing G. The health consequences of alcohol and drug abuse Health in Sweden: The National Public Health Report 2012. Chapter 11. Scandinavian journal of public health. 2012; 40(9) Suppl: 211-28.

44. Room R, Babor T, Rehm J. Alcohol and public health. Lancet. 2005; 365(9458): 519-30.

45. Lucas GM, Gebo KA, Chaisson RE, Moore RD. Longitudinal assessment of the effects of drug and alcohol abuse on HIV-1 treatment outcomes in an urban clinic. Aids. 2002; 16(5): 767-74.

46. Stein DJ, Aguilar-Gaxiola S, Alonso J, Bruffaerts R, de Jonge P, Liu Z, et al. Associations between mental disorders and subsequent onset of hypertension. Gen Hosp Psychiatry. 2014; 36(2): 142-9.

47. Carr CP, Martins CM, Stingel AM, Lemgruber VB, Juruena MF. The role of early life stress in adult psychiatric disorders: a systematic review according to childhood trauma subtypes. J Nerv Ment Dis. 2013; 201(12): 1007-20.

48. Najt P, Fusar-Poli P, Brambilla P. Co-occurring mental and substance abuse disorders: a review on the potential predictors and clinical outcomes. Psychiatry Res. 2011; 186(2): 159-64.

49. Zimmermann US, Blomeyer D, Laucht M, Mann KF. How gene-stress-behavior interactions can promote adolescent alcohol use: the roles of predrinking allostatic load and childhood behavior disorders. Pharmacol Biochem Behav. 2007; 86(2): 246-62.

50. Pettinati HM, O'Brien CP, Dundon WD. Current status of cooccurring mood and substance use disorders: a new therapeutic target. Am J Psychiatry. 2013; 170(1): 23-30.

51. Díaz Heredia LP, Marziale MHP. El papel de los profesionales en centros de atención en drogas en ambulatorios de la ciudad de Bogotá, Colombia. Rev Latino-Amer Enfermagem. 2010; 18: 573-81. 